\title{
UNITY POWER FACTOR CONTROL BY PWM RECTIFIER
}

\author{
Imran syed ${ }^{1}$, M. Bala Subba Reddy ${ }^{2}$, K. Hari Babu ${ }^{3}$ \\ ${ }^{1}$ M.Tech Scholar (P.E), ${ }^{2}$ Professor \& H.O.D, ${ }^{3}$ Professor\&Vice Principal, Department of EEE \\ Prakasam Engineering College, Kandukur, Prakasam Dist, AP, INDIA
}

\begin{abstract}
This paper analyzes the principle of PWM rectifier and presents a unity power factor control method of PWM rectifier. Controller used double closed-loop PI control, which inner uses three-phase input current control method controlled by unity power factor and outer controls the output DC voltage of rectifier. Voltage phase detection methods which proposed could eliminate the affection of the voltage harmonics on phase detection accuracy. The result of the simulation and experiment verify the feasibility and effectiveness of the method.
\end{abstract}

Keywords- PWM, rectifier, unity power factor, filter

\section{INTRODUCTION}

Since the rectifier consisted of diode or thyristor is easy to control and reliable, it is widely used in industry. However, the input current of this rectifier contains a large number of harmonics, which has become to the main source of grid. In addition, this rectifier also has the issue about low power factor. PWM rectifier does not produce harmonics on the grid, while the input power factor can be controlled and the output DC voltage can be adjustable, is a high performance fairing. In this paper, a PWM rectifier is studied, which focus on a unity power factor control method. The result of the simulation and experiment show the feasibility and effectiveness of the method [1].

\section{PWM RECTIFIER AND ITS UNITY POWER}

\section{FACTOR CONTROL METHOD SELECTING A}

\section{TEMPLATE}

Figure 1 shows the structure of the PWM rectifier. $e_{a}(t), e_{b}(t)$, $e_{c}(t)$ is the three phase voltages. $\mathrm{L}$ is the support filtering inductance of the AC side voltage. $\mathrm{R}$ is the equivalent resistance of the system. $\mathrm{C}$ is the support capacitance of the DC side voltage.

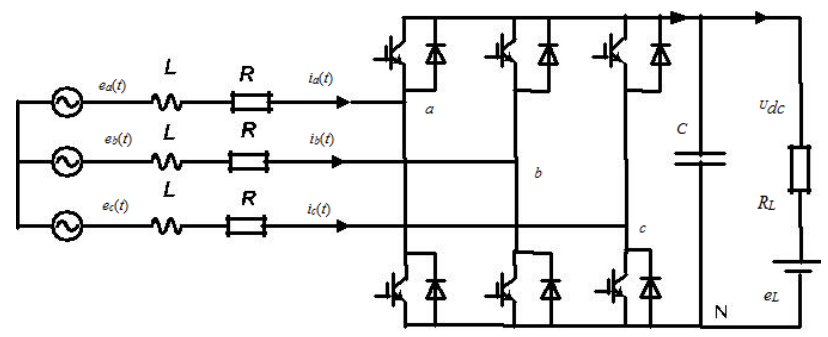

Fig.1 The structure of the PWM rectifier
When the load force ${ }^{e L}$ is zero or less than the DC voltage across the capacitor, the DC side is a purely resistive load and the rectifier operates in the rectifier mode. When the load force

${ }^{e L}$ is greater than the DC voltage across the capacitor; the rectifier operates in active inverter mode.

Figure 2 shows the direct power control method block diagram of the PWM rectifier. Controller used double closed-loop PI control, which inner uses three-phase input current control method controlled by unity power factor and outer controls the output DC voltage of rectifier, to control the power of the rectifier.

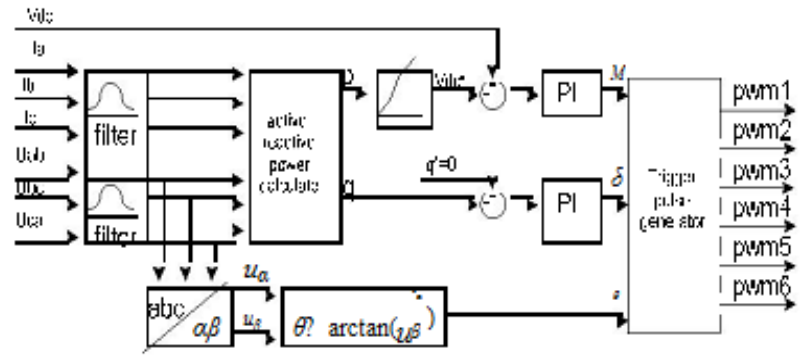

Fig.2 The direct power control method block diagram of the PWM rectifier

This control method of the control system is implemented as follows:

1).Detection the instantaneous fundamental component of the voltage and current. Using the second-order Butterworth digital filtering algorithm of equation 1, the amplitude, phase and frequency characteristics of this filter is shown in figure 3. 


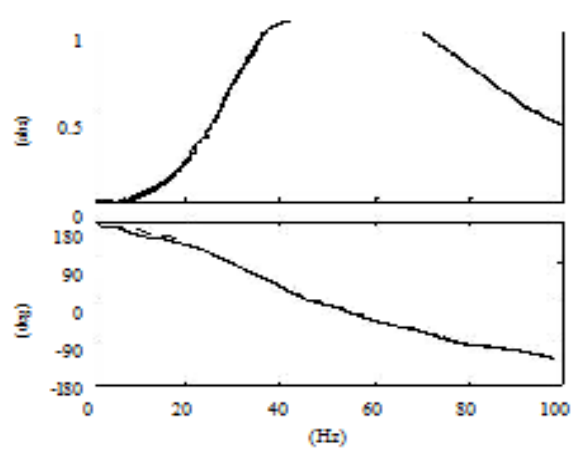

Fig.3 The amplitude, phase and frequency characteristics of Butterworth band-pass filter

From which we can see, amplitude of the fundamental component part of the signal does not decay, the phase does not shift, which on the basis of ensuring filters the DC component of the input signal and high harmonics.

$$
{ }_{1}=\frac{0.001915 z^{-1}-0.001971 z^{-2}-0.0018033948 z^{-3} \square 0.001859 z^{-4}}{1-3.903 z-1+5.722 z^{-2}-3.734 z-3+0.915 z-4}
$$

The sampling frequency of the discrete formula is $5000 \mathrm{~Hz}$, and filter quality factor of the design is 1 [3].

2) Calculate the instantaneous active power and reactive power. Obtain the input active power and reactive power via the calculation of equation 2 and equation 3 .

$$
\begin{aligned}
& p=U a * I a+U b * I b+U c * I c \\
& q=((U a-U b) * I a+(U b-U c) * I b+(U c-U a) * \\
& I c) / 3
\end{aligned}
$$

3) Calculate the average active power, reactive power and DC voltage in each cycle. Using the average formula of equation 4 to obtain the input active power, reactive power and $\mathrm{dc}$ capacitor voltage of the rectifier

$$
X=\sum X_{i} i=1,2 \ldots 100 X \quad \begin{gathered}
100 \\
1
\end{gathered}=p, q, v d c
$$

4) For reactive power $q$, the use of the inner PI control algorithm make the input reactive power of the rectifier is zero, which achieve the unity power factor input. The block diagram to achieve the inner PI control algorithm is shown in Figure 4.

$-\delta$

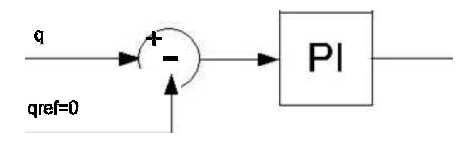

Fig.4 The inner loop PI controller of power factor 5) For the DC voltage across the capacitor, use of the outer PI control algorithm and adjust the output DC voltage across the capacitor of the rectifier, thus control the output power. The block diagram to achieve the outer PI control algorithm is shown in Figure 5 [4].

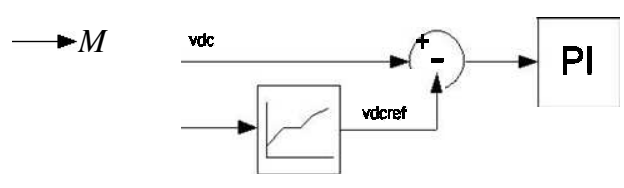

Fig.5 The outer loop PI controller of power

6) Obtain the real-time phase of the grid. The three-phase fundamental voltage obtained in Step 1) can obtain the realtime phase information of the grid by using formula 5 , formula 6 and formula 7.

$$
\begin{gathered}
u_{\alpha}=u_{a}-0.5 * u_{b} \quad-0.5 * u_{c} \\
\begin{array}{cl}
u_{\beta}=-0.86 * u_{b} & -0.65 * u_{c} \\
\theta & \stackrel{u_{\alpha}}{-\arctan (} \\
u_{\beta}
\end{array}
\end{gathered}
$$

7) Obtain the three-phase output current reference value. Use formula 8 to obtain the three-phase output current reference value.

$$
\begin{aligned}
& i a \square M^{*} \sin (\theta \square \delta) \\
& i b \square M^{*} \sin (\theta \square \delta-120) \\
& \text { ic } \square M^{*} \sin (\theta \square \delta \square 120)
\end{aligned}
$$

The output of PWM signal Switch the output current reference value of rectifier to the switching time of each switch device[5].

\section{THE SIMULATION AND EXPERIMENTAL} VERIFICATION OF PWM RECTIFIER SYSTEM

\section{AND ITS RESULTS ANALYSIS}

Design the control system strategies of verification and the method to achieve unity power factor in 30KVA rectifier. The main parameter of the rectifier system is shown in Table 1: 
Table 1: The Parameters of the Rectifier System

\begin{tabular}{cc} 
System Vol tage & $380 \mathrm{~V}$ \\
\hline Short-Circuit Capacity of the Power Grid & $20 \mathrm{MVA}$ \\
\hline Equivalent inductance of the Power Grid & $0.023 \mathrm{mH}$ \\
\hline Equivalent resistance of the Power Grid & $0.0024 \Omega$ \\
\hline AC connected inductance of the Rectifier & $3 \mathrm{mH}$ \\
\hline Equivalent AC resistance of the Rectifier & $0.0942 \Omega$ \\
\hline DC-side capacitance of the Rectifier & $4500 \mathrm{uf}$ \\
\hline Rectifier capacity & $30 \mathrm{KVA}$ \\
\hline Rated input current rectifier & $45.5 \mathrm{~A}$ \\
\hline Rated output voltage rectifier & $640 \mathrm{~V}$ \\
\hline Rated resistiveload & $12 \Omega$ \\
\hline Maximum feedback vol tage & $1280 \mathrm{~V}$ \\
\hline Inner loop control & Unity power \\
\hline Outer loop control & factor control \\
\hline Pulse trigger & Direct power \\
\hline Switching frequency & control \\
\hline Fundamental current detection method & SPWM method \\
\hline & $5 \mathrm{KHz}$ \\
\hline
\end{tabular}

Building a PWM rectifier simulation system in MATLAB/SIMULINK Figure 6 shows the input voltage, input current and output voltage waveform when the rectifier works in rectifying mode.

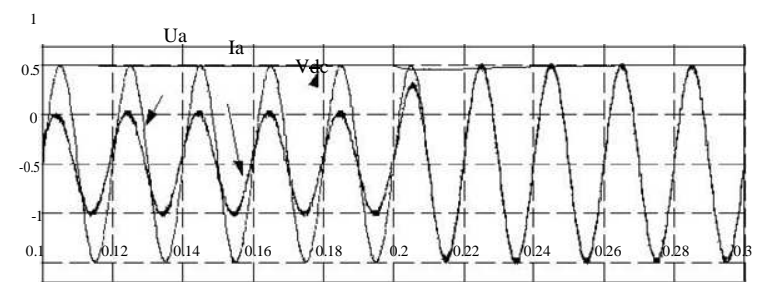

Fig.6 The input voltage, input current and output voltage waveform when the rectifier work in rectifying mode

In the $0.2 \mathrm{~s}$, rectifier load suddenly increased from $50 \%$ rated load to $100 \%$ rated load, rectifier input current adjusted to the steady state point after half a cycle, rectifier output voltage resumed a given rated voltage after about two cycles. In the process of the steady state and dynamic adjustment, the input voltage of PWM rectifier are kept in phase with the output current and the input power factor maintained to 1 .

Figure 7 shows the input voltage, input current and output voltage waveform when the rectifier works in the inverter energy feedback mode.

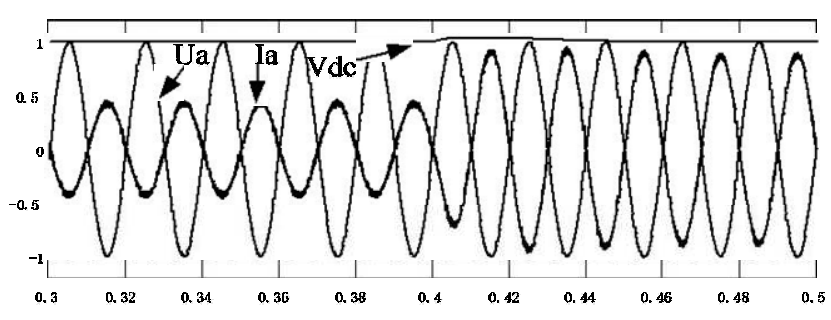

Fig.7 The input voltage, input current and output voltage waveform when the rectifier work in the inverter energy feedback mode

In the case of the maximum feedback voltage of $1280 \mathrm{~V}$, in the $0.4 \mathrm{~s}$, rectifier load suddenly increased from $50 \%$ rated load to $100 \%$ rated load, rectifier input current adjusted to the steady state point after half a cycle, rectifier output voltage resumed a given rated voltage after about two cycles. In the process of the steady state and dynamic adjustment, the input voltage of PWM rectifier are kept phase contrast with the output current and the input power factor maintained to 1 .

Figure 8 shows the input voltage, input current and output voltage waveform when the rectifier switches from rectifying mode to inverter mode.

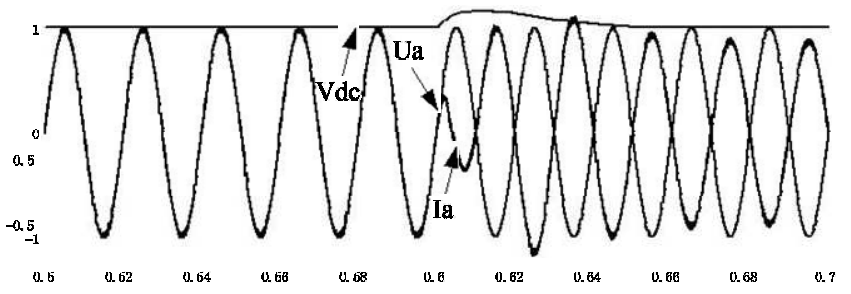

Fig.8 The input voltage, input current and output voltage waveform in the rectify switching time

In the $0.46 \mathrm{~s}$, rectifier switches automatically from the rectifying mode to inverter mode, rectifier input current switches from the rectifying steady state to the inverter feedback steady state after about two and a half cycle, rectifier output voltage returns to a given rated voltage after about three cycles. In the process of the steady state and dynamic adjustment, In addition to the half-power cycles when rectifier switches from the rectifying mode to inverter mode, the PWM rectifier input power factor maintained to 1 .

Using STM32F103C8, ARM-M3 core 32-bit MCU, as the core control chip build the experimental system to verify the control strategy and unity power factor control method.

Figure 9 shows the instantaneous input voltage and input current waveform collected by Hioki 3196 power quality analyzer when the rectifier working in the rectifying mode. 


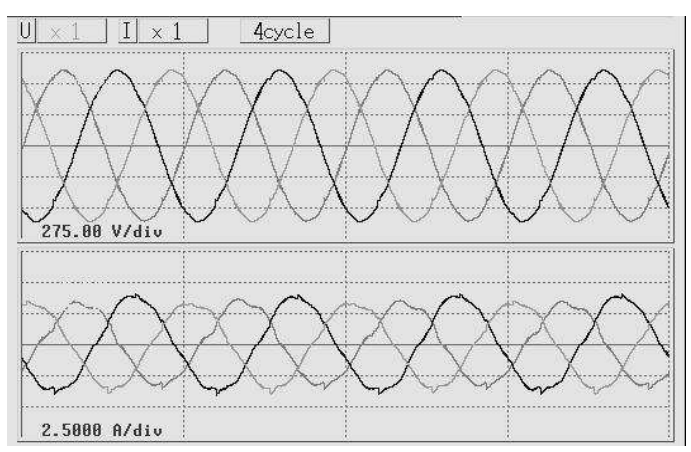

Fig.9 The instantaneous input voltage and input current of rectifier

Figure 10 shows the input line-voltage $\mathrm{Uab}$ and input linecurrent Ia waveform collected by Tektronix tps2024 oscilloscope when rectifier switches from diode rectifying to PWM rectifier. There into, Uab stays ahead of Ia 30 degree and input power factor is 1 .

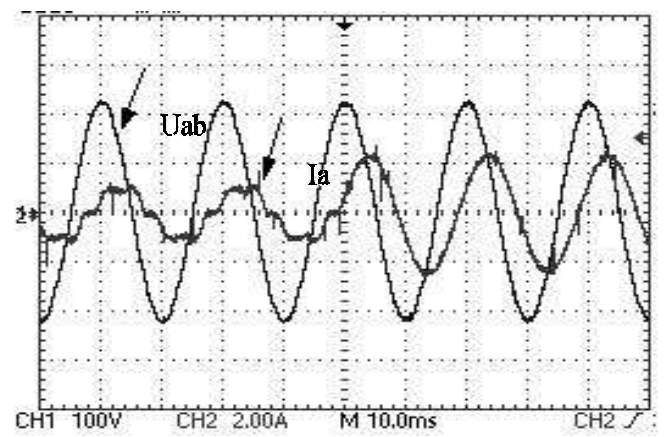

Fig.10 The input voltage and input current waveform when the rectifier works in rectifying mode

Figure 11 shows the input line-voltage $U a b$ and input linecurrent Ia waveform when the PWM rectifier works in the inverter energy feedback mode. There into, Uab lags behind Ia 150 degree and input power factor is -1 .

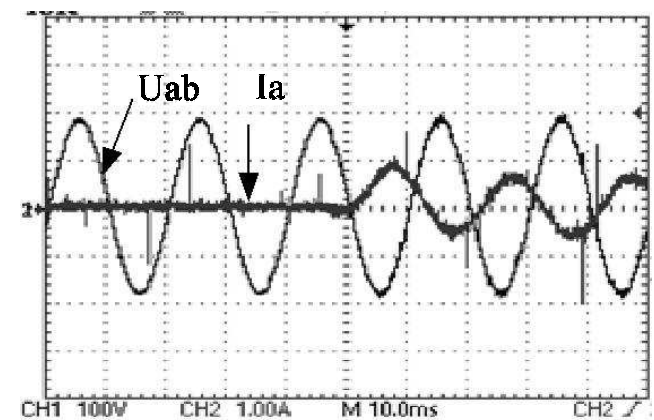

Fig.11 The input voltage and input current waveform when the rectifier works in the inverter mode
Operating parameters when rectifier has different load conditions are shown in Table 2. There into, the maximum load is $2 \mathrm{~kW}$.

Table 2 Rectifier Operating State

\begin{tabular}{|c|c|c|c|c|c|c|}
\hline Resistance & 150 & 200 & 300 & 600 & 900 & 2000 \\
\hline Uab & 309.4 & 310.9 & 312.5 & 311.0 & 311.0 & 314.5 \\
\hline Ubc & 309.8 & 311.8 & 314.9 & 311.3 & 310.0 & 313.3 \\
\hline Uca & 309.4 & 310.4 & 313.3 & 312.0 & 310.0 & 313.2 \\
\hline Ia & 3.59 & 2.40 & 1.54 & 0.77 & 0.53 & 0.27 \\
\hline Ib & 3.72 & 2.49 & 1.60 & 0.81 & 0.55 & 0.28 \\
\hline Ic & 3.96 & 2.65 & 1.70 & 0.88 & 0.59 & 0.30 \\
\hline Pin & 2010 & 1355 & 879 & 444 & 301 & 154 \\
\hline PF & 0.998 & 0.999 & 0.998 & 0.997 & 0.997 & 0.997 \\
\hline Vdc & 536 & 515 & 511 & 508 & 506 & 518 \\
\hline Pout & 1915 & 1326 & 870 & 430 & 284 & 134 \\
\hline THDIa\% & 1.46 & 1.69 & 2.43 & 4.01 & 5.57 & 10.06 \\
\hline THDIb\% & 1.41 & 1.60 & 2.23 & 3.72 & 5.09 & 9.27 \\
\hline THDIc\% & 1.81 & 1.96 & 2.47 & 3.98 & 5.27 & 8.56 \\
\hline Load \% & 100 & 67.7 & 43.5 & 22.2 & 15.1 & 7.7 \\
\hline Efficiency \% & 95.27 & 97.85 & 99.1 & 96.84 & 94.35 & 87.01 \\
\hline
\end{tabular}

The table shows that in most of the load, the three-phase input current of rectifier are basically equation, less harmonic distortion and the conversion efficiency of rectifier is over $90 \%$. In the case of any load, the input power factor of rectifier are greater than 0.995 , indicating that using the unit power factor achieve method is feasible and effective.

\section{CONCLUSIONS}

This paper analyzes the principle of PWM rectifier, and presents a input unity power factor control method of PWM rectifier. The result of the simulation and experiment verify the feasibility and effectiveness of the method.

\section{ACKNOWLEDGMENTS}

This research was supported by Shaanxi provincial project of special foundation.

\section{REFERENCES}

[1] The Research and Development of the High Performance Dual PWM AC Drives. PhD thesis. 1997

[2] Zhang Chongwei, Zhang Xing. PWM Rectifier and its Control. Beijing Mechanical Industry Press. 2003. 
[3] Wang Zhaoan, Zhang Mingxun, Power Electronic Equipment Design and Application Manual [M].Beijing Mechanical Industry Press. 2002:675-676.

[4] Wang Jiuhe. The Non-linear Control of Voltage-type PWM rectifier. Mechanical Industry Press. 2008.

[5] Study of the Control Techniques of System Waveform of High Power and High Frequency PWM Reversible Rectifier. PhD thesis. Huazhong University of Science and Technology, 1997 